Mathematical Modelling and Analysis

Volume 4, 1999, PAGeS 33-43

(C) 1999 Technika

\title{
SIMULATION OF STEADY - STATE HEAT PROCESS FOR THE RECTANGULAR FIN - CONTAINING SYSTEM
}

\author{
M. BUIKE ${ }^{1}$ \\ Institute of Mathematics \\ Latvian Academy of Sciences and University of Latvia
}

Akadēmijas laukums 1, LV-1524 Rīga, Latvia

E-mail: buikis@latnet.lv

Received October 14, 1999

\begin{abstract}
In this paper three analytical solution for $2 D$ temperature distribution in the wall and fin are considered solution. The results of calculations are compared with the analytical.
\end{abstract}

\section{INTRODUCTION}

Approximate analytical solution are very useful for heat transfer problems in systems with the fin. Heggs and Stones [4] in 1980 gave an analytical solution for $1 D$ model of longitudal (and annular) fin assemblies. Buikis [2] in 1995 constructed an analytical solution for $2 D$ model. He developed with original technique: the conservative averaging method. Weakness of this solution was continuity of the temperature only in regard to the averaged values on two lines: those between the fin and the wall and the upper and lower parts of the wall. Malik, Wood and Buikis [5] modified the conservative averaging method and achieved the continuity of the temperature for all points of the wall. Buike and Buikis [1] and Buikis and Buike [3] gave a modification [1] and generalization [3] of the conservative averaging method. The approximate analytical solution obtained in [1], [3] is continuous in the whole region.

The aim of this paper is to compare, both analytically and numerically, three solutions from [1], [2] and [5].

\footnotetext{
${ }^{1}$ This work was supported by Latvian Council of Science under grant 96.0779.
} 


\section{STATEMENT OF THE PROBLEM}

We consider a periodical system with a rectangular fin whose elements, in dimensional arguments, are a wall $\{\bar{x} \in[0, \Delta], \bar{y} \in[0, B+R]\}$ and a fin $\{\bar{x} \in[\Delta, \Delta+L], \bar{y} \in[0, B]\}$. Here $2 B$ is the fin thickness, $2 R$ is the distance between two adjacent fins; $L$ stands for the fin length, and $\Delta$ denotes the wall thickness. We use the dimensionless arguments

$$
x=\frac{\bar{x}}{B+R}, y=\frac{\bar{y}}{B+R},
$$

the dimensionless parameters

$$
\delta=\frac{\Delta}{B+R}, l=\frac{L}{B+R}, b=\frac{B}{B+R},
$$

and the dimensionless temperatures

$$
U_{0}=\frac{\bar{U}_{0}-U_{a}}{U_{b}-U_{a}}, U=\frac{\bar{U}-U_{a}}{U_{b}-U_{a}}
$$

where $U_{b}$ and $U_{a}$ are the temperatures of surroundings on the left of the wall $($ at $x<0)$ and on the right of the wall, respectively.

The parameters of boundary conditions are as follows:

$$
\beta_{0}^{0}=\frac{h_{0}(B+R)}{k_{0}}, \beta_{0}=\frac{h(B+R)}{k_{0}}, \beta=\frac{h(B+R)}{k},
$$

where $k_{0}(k)$ is the heat conduction coefficient for the wall (relative to the fin); $h_{0}(h)$ is Newton's coefficient of heat exchange with the surroundings on the left (right) sides.

The stationary heat process in such a system is described as follows:

$$
\begin{aligned}
& \frac{\partial^{2} U_{0}}{\partial x^{2}}+\frac{\partial^{2} U_{0}}{\partial y^{2}}=0, \quad 0<x<\delta, 0<y<1, \\
& \frac{\partial^{2} U}{\partial x^{2}}+\frac{\partial^{2} U}{\partial y^{2}}=0, \quad \delta<x<\delta+l, 0<y<b \\
& \frac{\partial U_{0}}{\partial x}+\beta_{0}^{0}\left(1-U_{0}\right)=0, \quad x=0,0<y<1 \\
& \frac{\partial U_{0}}{\partial x}+\beta_{0} U_{0}=0, \quad x=\delta, b<y<1 \\
& \frac{\partial U}{\partial y}+\beta U=0, \quad \delta<x<\delta+l, y=b \\
& \frac{\partial U}{\partial x}+\beta U=0, \quad x=\delta+l, 0<y<b
\end{aligned}
$$




$$
\begin{aligned}
& \left.\frac{\partial U_{0}}{\partial y}\right|_{y=0}=\left.\frac{\partial U_{0}}{\partial y}\right|_{y=1}=0, \quad 0<x<\delta, \\
& \left.\frac{\partial U}{\partial y}\right|_{y=0}=0, \quad \delta<x<\delta+l
\end{aligned}
$$

$$
\left.U_{0}\right|_{x=\delta-0}=\left.U\right|_{x=\delta+0},\left.\quad \beta \frac{\partial U_{0}}{\partial x}\right|_{x=\delta-0}=\left.\beta_{0} \frac{\partial U}{\partial x}\right|_{x=\delta+0}, \quad 0<y<b
$$

\section{SOLUTION FOR THE FIN}

We will seek a solution to the problem for the fin in the form:

$$
U(x, y)=f_{0}(x)+\left(e^{\rho y}-1\right) f_{1}(x)+\left(1-e^{-\rho y}\right) f_{2}(x), \rho=b^{-1},
$$

where $f_{i}(x), i=0,1,2$ are unknown functions. Now we will define the mean integral value of the function $U(x, y)$ in the $y$-direction:

$$
u(x)=\rho \int_{0}^{b} U(x, y) d y
$$

The boundary conditions (2.8), (2.11), and equality (3.2) allow us to eliminate all $f_{i}(x)$ from $(3.1)$. This means that the representation of solution $U(x, y)$ for the fin can be reduced to the form:

$$
U(x, y)=u(x) \Phi(y)
$$

where

$$
\Phi(y)=\frac{\sinh (1)+\beta b(\cosh (1)-\cosh (\rho y))}{\sinh (1)+\beta b(\cosh (1)-\sinh (1))} .
$$

We can find the differential equation for $u(x)$ by integrating the basic equation (2.5) and using boundary condition (2.8) and (2.11):

$$
\frac{d^{2} u(x)}{d x^{2}}-\mu^{2} u(x)=0, \quad \delta<x<\delta+l,
$$

where $\mu^{2}=\frac{\beta}{b} \Phi(b)$. We can employ the integrated in the $y$-direction boundary condition (2.9), which allows us to write a solution to equation (3.5) in the form with one arbitrary constant $C_{1}$ :

$$
u(x)=C_{1}\left(\mu_{1} e^{\mu x}+e^{-\mu x}\right) .
$$


Here

$$
\mu_{1}=\frac{\mu-\beta}{\mu+\beta} e^{-2 \mu(\delta+l)} .
$$

It means that the solution for the fin can be written in the form:

$$
U(x, y)=C_{1}\left(\mu_{1} e^{\mu x}+e^{-\mu x}\right) \Phi(y) .
$$

Later, we will find constant $C_{1}$ from the conjunction solutions for the fin and the two mentioned parts of the wall.

\section{SOLUTION FOR THE UPPER PART OF THE WALL}

We express the exponential approximation for the wall in the $x$ direction in the form:

$$
U_{0}(x, y)=g_{0}(y)+\left(e^{d(\delta-x)}-1\right) g_{1}(y)+\left(1-e^{d(x-\delta)}\right) g_{2}(y),
$$

where $d=\delta^{-1}$.

Next, we define the integral mean in the $x$-direction:

$$
u_{0}(x)=d \int_{0}^{\delta} U_{0}(x, y) d x
$$

The boundary condition(2.6) and equality (4.2) allow us to obtain the following expressions for $g_{1}(y)$ and $g_{2}(y)$ :

$$
g_{i}(y)=(-1)^{i}\left(-a_{i} g_{0}(y)+b_{i} u_{0}(y)-d_{i}\right),
$$

Here

$$
a_{i}=\frac{A_{i}}{K_{1}}, \quad b_{i}=\frac{B_{i}}{K_{1}}, \quad d_{i}=\frac{D_{i}}{K_{1}}, \quad i=1,2 .
$$

Here $K_{1}=e^{-1}\left(2+\beta_{0}^{0} \delta(e-1)(3-e)\right)$,

$$
\begin{gathered}
A_{1}=e^{-1}\left(1+\beta_{0}^{0} \delta(e-2)\right), \quad B_{1}=e^{-1}\left(1+\beta_{0}^{0} \delta(e-1)\right), \quad D_{1}=e^{-1} \beta_{0}^{0} \delta, \\
A_{2}=e+\beta_{0}^{0} \delta, \quad B_{2}=e+\beta_{0}^{0} \delta(e-1), \quad D_{2}=\beta_{0}^{0} \delta(e-2) .
\end{gathered}
$$

Now, can rewrite the representation (4.1) for $U(x, y)$ in a form:

$$
\begin{aligned}
U_{0}(x, y)= & \left(1+\left(e^{d(\delta-x)}-1\right) a_{1}-\left(1-e^{d(x-\delta)}\right) a_{2}\right) g_{0}(y)+\left(\left(1-e^{d(x-\delta)}\right) b_{2}\right. \\
& \left.-\left(e^{d(\delta-x)}-1\right) b_{1}\right) u_{0}(y)+\left(e^{d(\delta-x)}-1\right) d_{1}-\left(1-e^{d(x-\delta)}\right) d_{2}(.4 .3)
\end{aligned}
$$

Further transformations are associated with conditions on the right border $x=\delta$ of the wall. These conditions are different for the interval $[0, b]$ and 
for the interval $[b, 1]$. We require now that representation (4.3) fulfills the boundary condition (2.7). This gives

$$
g_{0}(y)=b_{0} u_{0}(y)-d_{0}, \quad b_{0}=\frac{B_{0}}{K_{0}}, \quad d_{0}=\frac{D_{0}}{K_{0}},
$$

Here

$$
\begin{gathered}
K_{0}=A_{2}-A_{1}+\beta_{0} \delta K_{1}=e-e^{-1}+2 \beta_{0}^{0} \delta e^{-1}+\beta_{0} \delta K_{1}, \\
B_{0}=B_{2}-B_{1}=e^{-1}\left(e^{2}-1+\beta_{0}^{0} \delta(e-1)^{2}\right), \\
D_{0}=D_{2}-D_{1}=\beta_{0}^{0} \delta\left(e-e^{-1}-2\right) .
\end{gathered}
$$

The expression (4.4) allows representation (4.3) to be rewritten in the form

$$
\begin{aligned}
U_{0}(x, y) & =\left(b_{0}+\left(a_{1} b_{0}-b_{1}\right)\left(e^{d(\delta-x)}-1\right)+\left(b_{2}-a_{2} b_{0}\right)\left(1-e^{d(x-\delta)}\right)\right) u_{0}(y) \\
& -d_{0}+\left(d_{1}-a_{1} d_{0}\right)\left(e^{d(\delta-x)}-1\right)+\left(a_{2} d_{0}-d_{2}\right)\left(1-e^{d(x-\delta)}\right) . \quad(4.5)
\end{aligned}
$$

Similarly to the fin case we can find a differential equation for the unknown function $u_{0}(y)$ by integrating the basic equation (2.4) in the $x$-direction and using expression (4.5) to find $\left.\frac{1}{\delta} \frac{\partial U_{0}}{\partial x}\right|_{x=0} ^{x=\delta}$. This yields

$$
\begin{aligned}
\frac{d^{2} u_{0}}{d y^{2}}-\kappa^{2} u_{0} & =-\Theta_{2}, \quad b<y<1, \\
u_{0}^{\prime}(1) & =0,
\end{aligned}
$$

where

$$
\begin{gathered}
\kappa^{2}=2 \delta^{-2} K_{0}^{-1}\left(\left(\beta_{0}+\beta_{0}^{0}\right) \delta \sinh (1)+2 \beta_{0} \beta_{0}^{0} \delta^{2}(\cosh (1)-1)\right), \\
\Theta_{2}=\delta^{-2}\left(\left(d_{1}-a_{1} d_{0}\right)(e-1)+\left(d_{2}-a_{2} d_{0}\right)\left(1-e^{-1}\right)\right) .
\end{gathered}
$$

The general solution of equations (4.6), (4.7) is

$$
u_{0}(y)=C_{2} \cosh (\kappa(1-y))+U_{2}, U_{2}=k^{-2} \Theta_{2},
$$

with an arbitrary constant $C_{2}$.

\section{SOLUTION FOR THE LOWER PART OF THE WALL}

First, we integrate the basic differential equation (2.4)

$$
\frac{d^{2} u_{0}(y)}{d y^{2}}+\left.\frac{1}{\delta} \frac{\partial U_{0}}{\partial x}\right|_{x=0} ^{x=\delta}=0
$$


Next, we require fulfillment of first conjugation condition (2.12). From (3.8) and (4.3) it follows that

$$
g_{0}(y)=C_{1}\left(1+\mu_{1}\right)\left(\Phi_{0}-\Phi_{1} \cosh (\rho y)\right),
$$

Where

$$
\begin{array}{r}
\Phi_{1}=\left((\beta b)^{-1} \sinh (1)+\cosh (1)-\sinh (1)\right)^{-1}, \\
\Phi_{0}=\left((\beta b)^{-1} \sinh (1)+\cosh (1)\right) \Phi_{1} .
\end{array}
$$

We can substitute now expression (5.2) for $g_{0}(y)$ in representation (4.3) and calculate the derivative of $U_{0}(x, y)$ at the point $x=\delta$. Let us substitute both expressions into equation (5.1). This gives

$$
\frac{d^{2} u_{0}}{d y^{2}}-\lambda^{2} u_{0}=-D_{3}-C_{1} \Theta_{3,0}+C_{1} \Theta_{3,1} \cosh (\rho y) .
$$

Here

$$
\begin{gathered}
\lambda^{2}=\frac{\beta_{0}^{0}(e-1)^{2}}{e \delta K_{1}}, \quad D_{3}=\frac{2 \beta_{0}^{0}}{e \delta K_{1}}, \quad \Theta_{3, i}=\Theta_{3} \Phi_{i}, \quad i=0,1, \\
\Theta_{3}=\frac{\left(A_{1} e-A_{2} e^{-1}\right)\left(1+\mu_{1}\right)}{\delta^{2} K_{1}}-\frac{\beta_{0} \mu}{\beta \delta}\left(1-\mu_{1}\right) .
\end{gathered}
$$

The solution of equation (5.3) with boundary condition $u^{\prime}(0)=0$ reads as follows:

$$
u_{0}(y)=C_{3} \cosh (\lambda y)+C_{1} U_{3}+C_{1} U_{4} \cosh (\rho y)+d_{3},
$$

where

$$
U_{3}=\frac{\Theta_{3,0}}{\lambda^{2}}, U_{4}=\frac{\Theta_{3,1}}{\rho^{2}-\lambda^{2}}, \quad d_{3}=\frac{D_{3}}{\lambda^{2}} .
$$

Again, $C_{3}$ in equation (5.4) is a free constant.

\section{THE ESTIMATION OF FREE CONSTANTS $C_{1}, C_{2}, C_{3}$}

First, we require that the temperature at the right upper corner point $(0, b)$ of the fin equals that of the upper part of the wall at the same point. Then we obtain from (3.8), (4.4), (4.8):

$$
C_{1}\left(e^{-\mu \delta}+\mu_{1} e^{\mu \delta}\right) \Phi(b)=C_{2} b_{0} \cosh (\kappa(1-b))+U_{2} b_{0}-d_{0} .
$$

The next two conditions will be associated with the contact line between the upper and the lower parts of the wall. Coincidence of the average temperatures gives from (4.8) and (5.4):

$$
C_{2} \cosh (\kappa(1-b))+U_{2}=C_{3} \cosh (\lambda b)+C_{1}\left(U_{4} \cosh (1)+U_{3}\right)+d_{3} .
$$


Coincidence of the average fluxes on the line $y=b$ yields the condition:

$$
-C_{2} \kappa \sinh (\kappa(1-b))=C_{3} \lambda \sinh (\lambda b)+C_{1} U_{4} \rho \cosh (1) .
$$

Hence we have a system of three linear algebraic equations. This means that all these free constants can be obtained and thus the approximate analytical solution of the problem (2.4) - (2.12) is found uniquely.

We can easily show that the function $U_{0}(x, y)$ is continuous on the line $y=b$, i.e.

$$
\lim _{y \rightarrow b+0} U_{0}(x, y)=\lim _{y \rightarrow b-0} U_{0}(x, y) .
$$

In reality, we have the representation (4.3) for all points of the wall. It follows from (5.2) and (6.1) that $g_{0}(y)$ is continuous at the point $y=b$. In turn, it follows from (6.2) that $u_{0}(y)$ is continuous at the point $y=b$.

\section{THE APPROXIMATE SOLUTION FROM [2]}

The first approximate analytical solution based on conservative averaging method was obtained by Buikis [2]. The solution for the fin and the upper part of the wall was practically the same as described above. In turn, the solution for the lower part of the wall was constructed in a different manner.

Representation (4.1) together with boundary conditions (2.6) and (2.7) makes it possible to find a relation between $g_{1}(y)$ and $g_{0}(y)$ for upper part of the wall as

$$
g_{1}(y)=-\gamma g_{0}(y)+T,
$$

where

$$
\gamma=\frac{\beta_{0}^{0} \delta e+\beta_{0} \delta\left(1+\beta_{0}^{0} \delta(e-1)\right)}{(e-1)\left(e+1+\beta_{0}^{0} \delta(e-1)\right)} .
$$

Buikis assumed in paper [2] a relation similarly to (7.1) for the lower part of the wall

$$
g_{1}(y)=-\gamma g_{0}(y)+T_{1},
$$

with $T_{1}$ being unknown.

Relation (7.3) together with boundary condition (2.6) allows us to exclude $g_{1}(y)$ and $g_{2}(y)$ from representation (4.1). After integration in the $x$-direction this representation gives us the relation:

$$
u_{0}(y)=\varphi_{1} g_{0}(y)+T_{2} .
$$

Here

$$
\varphi_{1}=\frac{1+\beta_{0}^{0} \delta(e-2)}{1+\beta_{0}^{0} \delta(e-1)}+\frac{\gamma\left(2+\beta_{0}^{0} \delta(e-1)(3-e)\right)}{1+\beta_{0}^{0} \delta(e-1)},
$$




$$
T_{2}=\frac{\beta_{0}^{0} \delta-\left(2+\beta_{0}^{0} \delta(e-1)(3-e)\right) T_{1}}{1+\beta_{0}^{0} \delta(e-1)} .
$$

The integrable equation (2.4) was solved in regard to $g_{0}(y)$ in the form:

$$
g_{0}(y)=C_{3} \cosh \left(\kappa_{1} y\right)+T_{3},
$$

where

$$
\begin{gathered}
\kappa_{1}^{2}=\frac{(e-1)}{\delta^{2}} \frac{\gamma\left(e+1+2 \beta_{0}^{0} \delta(e-1)\right)-\beta_{0}^{0} \delta}{\left(1+\beta_{0}^{0} \delta(e-2)+\gamma\left(2+\beta_{0}^{0} \delta(e-1)(3-e)\right)\right)}, \\
T_{3}=\frac{\left(e+1+2 \beta_{0}^{0} \delta(e-1)\right) T_{1}-\beta_{0}^{0} \delta}{\gamma\left(e+1+2 \beta_{0}^{0} \delta(e-1)\right)-\beta_{0}^{0} \delta} .
\end{gathered}
$$

Now, we have four unknown constants $C_{1}, C_{2}, C_{3}$ and $T_{1}$. To define them we use first equation (6.1). The equation (6.2) due to (7.5), (7.6) transforms into

$$
C_{2} \cosh (\kappa(1-b))+U_{2}=\left(C_{3} \cosh \left(\kappa_{1} b\right)+T_{3}\right) \varphi_{1}+T_{2} .
$$

It is easy to see that equation (6.3) takes the form:

$$
-C_{2} \kappa \sinh (\kappa(1-b))=C_{3} \kappa_{1} \varphi_{1} \sinh \left(\kappa_{1} b\right) .
$$

As the last relation, the author in [2] uses a requirement, following from second condition (2.12) on the conjugation of average fluxes:

$$
\beta_{0} u^{\prime}(\delta)=\left.\frac{\beta}{b} \int_{0}^{b} \frac{\partial U_{0}}{\partial x}\right|_{x=\delta-0} d y
$$

which can be rewritten as

$$
C_{1} \beta_{0} \mu\left(\mu_{1} e^{\mu \delta}-e^{-\mu \delta}\right)=\left(C_{3} \frac{\sinh \left(\kappa_{1} b\right)}{\kappa_{1} b}+T_{3}\right) \beta \varphi_{2}-\psi_{2}
$$

where

$$
\begin{aligned}
\varphi_{2} & =\frac{\gamma(e-1)\left(e+1+\beta_{0}^{0} \delta(e-1)\right)-\beta_{0}^{0} \delta e}{1+\beta_{0}^{0} \delta(e-1)} \\
\psi_{2} & =\frac{(e-1)\left(e+1+\beta_{0}^{0} \delta(e-1)\right) T_{1}-\beta_{0}^{0} \delta e}{1+\beta_{0}^{0} \delta(e-1)} .
\end{aligned}
$$


Table 1.

Assembly temperature $\left(C^{0}\right)$ from [1].

\begin{tabular}{rcccccccc}
\hline$y / x$ & 0.000 & 0.195 & 0.391 & 0.586 & 0.586 & 1.260 & 1.934 & 2.608 \\
\hline 1.000 & 73.62 & 72.15 & 71.09 & 70.32 & & & & \\
0.714 & 73.53 & 72.05 & 70.99 & 70.23 & & & & \\
0.428 & 73.24 & 71.76 & 70.69 & 69.94 & & & & \\
0.142 & 72.77 & 71.27 & 70.20 & 69.44 & & & & \\
\hline 0.142 & 72.77 & 71.27 & 70.20 & 69.44 & 69.44 & 48.67 & 39.12 & 36.08 \\
0.094 & 72.62 & 71.14 & 70.14 & 69.50 & 69.50 & 48.70 & 39.14 & 36.09 \\
0.048 & 72.53 & 71.06 & 70.10 & 69.54 & 69.54 & 48.72 & 39.15 & 36.10 \\
0.000 & 72.51 & 71.04 & 70.09 & 69.55 & 69.55 & 48.72 & 39.16 & 36.10 \\
\hline
\end{tabular}

\section{THE APPROXIMATE SOLUTION FROM [5]}

The paper [5] is based on the ideas of [2], but with one important distinction: for the lower part of the wall for $U_{0}(x, y)$ there was given a representation in the $y$-direction (with the boundary condition (2.11) already fulfilled)

$$
U_{0}(x, y)=h_{0}(x)+2\left(\cosh \left(\frac{y}{b}\right)-1\right) h_{1}(x) .
$$

The basic equation (2.4) was integrated in the $y$-direction using integrable representation (8.1). This gives:

$$
\frac{d^{2} h_{0}}{d x^{2}}+2(\sinh (1)-1) \frac{d^{2} h_{1}}{d x^{2}}+\frac{1}{\delta^{2}} \sinh (1) h_{1}(x)=0, \quad 0<x<\delta .
$$

The function $h_{1}(x)$ was determined from the temperature continuity condition on the line $y=b$ :

$$
h_{1}(x)=\frac{U_{0}(x, b+0)-h_{0}(x)}{2\left(\cosh \left(\frac{y}{b}\right)-1\right)} .
$$

The three free constants $C_{1}, C_{2}$ and $C_{3}$ was found from the requirements: continuity of the temperature and flux on the 1 ine $x=\delta$ and of the flux on the line $y=b$.

\section{NUMERICAL COMPARISON OF THREE SOLUTIONS}

To illustrate the above solutions, the assembly is taken to be as in [4], [5] of mild steel with $k=k_{0}=45 \mathrm{~W} / \mathrm{mK}, h_{0}=266.5 \mathrm{~W} / \mathrm{m}^{2} \mathrm{~K}$ and $h=671.5 \mathrm{~W} / \mathrm{m}^{2} \mathrm{~K}$. Dimensions for the reference model, in $m$ are as follows: $\Delta=0.368 \cdot 10^{-2}, L=$ $0.12710^{-1}, B=0.445 \cdot 10^{-3}$ and $R=0.2695 \cdot 10^{-2}$. Temperatures of the surroundings are (in $C^{0}$ ) : $U_{a}=26, U_{b}=121$.

It is easy to see that [2] gives the poorest solution: the temperature field is discontinius on both lines $x=\delta$ and $y=b$. The best solution is that from [1] $(\operatorname{and}[3])$ : the temperature field is continuous in the whole region. 
Table 2.

Assembly temperature $\left(C^{0}\right)$ from $[5]$.

\begin{tabular}{rrrrrrrrr}
\hline$y / x$ & 0.000 & 0.195 & 0.391 & 0.586 & 0.586 & 1.260 & 1.934 & 2.608 \\
\hline 1.000 & 74.17 & 72.71 & 71.65 & 70.89 & & & & \\
0.714 & 74.08 & 72.61 & 71.56 & 70.79 & & & & \\
0.428 & 73.80 & 72.32 & 71.27 & 70.51 & & & & \\
0.142 & 73.33 & 71.85 & 70.78 & 68.42 & & & & 35.84 \\
\hline 0.142 & 73.33 & 71.85 & 70.78 & 68.42 & 68.42 & 48.13 & 38.81 & 35.86 \\
0.094 & 73.35 & 71.86 & 70.79 & 68.50 & 68.48 & 48.16 & 38.83 & 35.86 \\
0.048 & 73.36 & 71.87 & 70.79 & 68.62 & 68.51 & 48.18 & 38.84 & 35.84 \\
0.000 & 73.36 & 71.87 & 70.79 & 68.75 & 68.52 & 48.18 & 38.84 & 35.87 \\
\hline
\end{tabular}

Table 3.

Assembly temperature $\left(C^{0}\right)$ from $[2]$.

\begin{tabular}{ccccccccc}
\hline$y / x$ & 0.000 & 0.195 & 0.391 & 0.586 & 0.586 & 1.260 & 1.934 & 2.608 \\
\hline 1.000 & 73.40 & 71.92 & 70.86 & 70.10 & & & & \\
0.714 & 73.30 & 71.82 & 70.76 & 70.00 & & & & \\
0.428 & 73.02 & 71.52 & 70.46 & 69.70 & & & & \\
0.142 & 72.53 & 71.02 & 69.96 & 69.20 & & & & \\
\hline 0.142 & 75.90 & 73.38 & 68.89 & 61.94 & 69.20 & 48.54 & 39.05 & 36.02 \\
0.094 & 75.82 & 73.30 & 68.81 & 61.86 & 69.26 & 48.57 & 39.07 & 36.04 \\
0.048 & 75.77 & 73.25 & 68.76 & 61.81 & 69.30 & 48.59 & 39.08 & 36.05 \\
0.000 & 75.76 & 73.23 & 68.74 & 61.79 & 69.31 & 48.60 & 39.08 & 36.05 \\
\hline
\end{tabular}

\section{REFERENCES}

[1] M. Buike and A. Buikis. Two-dimensional solution for a longitudinal fin of rectangular profile. Latv. Univ. Zinātn. Raksti, 612, 1998, $33-44$.

[2] A. Buikis. Two-dimensional solution for heat transfer in a regular fin assembly. Latv. J. Phys. Tech. Sci., (5), 1995, $51-58$.

[3] A. Buikis and M. Buike. Closed two-dimensional solution for heat transfer in a periodical system with a fin. Proceedings of the Latvian Academy of Sciences, 52 (5), 1998, 218 222.

[4] P.J. Heggs and P.R. Stones. Effects of dimensions on the heat flowrate through extended surfaces. Trans. ASME J.Heat Transfer, 102, 1980, $180-182$.

[5] M.Y. Malik, A.S. Wood and A. Buikis. Approximate analytical solution for a $2 D$ wall fin assembly. J. mech. engng. sci., 1999, 18 p. (submited) 
STACIONARAUS ŠILUMOS LAIDUMO PROCESO MODELIAVIMAS STAC̈IAKAMPESE SRITYSE

M. BUIKE

Darbe nagrinèjamas stacionarus šilumos pasiskirstymas dviejų stačiakampių sričių junginyje. Apžvelgti analiziniai diferencialinio uždavinio sprendinio skleidiniai, įvertinamos jų taikymo ribos. Sudaryta baigtinių skirtumų schema ir apskaičiuotas skaitinis sprendinys, kuris palygintas su analiziniais sprendiniais. 